\title{
Glutamina para frangos de corte mantidos em termoneutralidade dos 21 aos 42 dias $^{1}$
}

\section{Glutamine for broilers from 21 to 42 days maintained in thermoneutral environment}

\author{
Érika Martins de Figueiredo ${ }^{2 a^{*}}$; Rita Flávia Miranda de Oliveira Donzele ${ }^{3}$; \\ Juarez Lopes Donzele ${ }^{4}$; Katiene Régia Silva Sousa ${ }^{5}$; Evandro Ferreira Cardoso ${ }^{2}$; \\ Aline Nantes Sélos ${ }^{6}$; Amanda Dione Silva²; Rodrigo de Freitas Jacob ${ }^{7}$
}

\section{Resumo}

Conduziu-se este estudo para avaliar os efeitos de níveis de glutamina na ração sobre o desempenho e carcaça de frangos de corte submetidos à ambiente de termoneutralidade no período de 21 a 42 dias de idade. Foram utilizados 168 frangos de corte machos da linhagem Cobb ${ }^{\circledR}$ de 21 a 42 dias de idade, distribuídos em delineamento experimental inteiramente casualizado, com quatro tratamentos, representados pelos níveis de glutamina das rações $(0,00 ; 0,50 ; 1,00$ e 1,50\%), sete repetições e seis aves por unidade experimental. Foram avaliados o desempenho, os rendimentos da carcaça, peito, coxa e sobrecoxa e a expressão do mRNA da proteína HSP70. Aos 21 dias e com peso inicial de $900 \pm$ $4,71 \mathrm{~g}$, as aves foram alojadas em câmaras climáticas com temperatura de $23,2 \pm 1,77^{\circ} \mathrm{C}$ e umidade relativa de $70 \pm 5,82 \%$ correspondendo ao ITGU calculado de $72 \pm 2,75$, caracterizando um ambiente de termoneutralidade. Não se observou efeito dos níveis de glutamina sobre o consumo de ração, ganho de peso e conversão alimentar das aves. Os níveis de glutamina não influenciaram os pesos absolutos e os relativos da carcaça, peito, coxa e sobrecoxa das aves. Não se observou efeito dos níveis de glutamina da ração na expressão do mRNA da proteína HSP70. Conclui-se que níveis de glutamina na ração não influenciaram o desempenho e as características de carcaça de frangos de corte dos 21 aos 42 dias de idade mantidos em ambiente termoneutro.

Palavras-chave: Ambiente térmico, aves, expressão gênica, HSP

\begin{abstract}
This study was conducted to evaluate the effects of dietary glutamine levels on performance and carcass traits of broilers kept in thermoneutral environment from 21 to 42 days of age. Hundred sixty eight male broilers $\mathrm{Cobb}{ }^{\circledR}$ with 21 days of age and initial body weight of $900 \pm 4.71 \mathrm{~g}$ were allotted in a completely randomized design with four levels of glutamine $(0.00,0.50,1.00$ and $1.50 \%)$, seven replicates with six birds each. Performance, relative weights of carcass, breast, thigh and drumstick and mRNA expression of HSP70 were evaluated. Birds were housed in environmental chambers with temperature of $23.2 \pm$
\end{abstract}

\footnotetext{
1 Parte da Dissertação de Mestrado da primeira autora apresentada ao Curso de Pós-Graduação em Zootecnia, Universidade Federal de Viçosa, UFV, Viçosa, MG. E-mail: erika_mfigueiredo@yahoo.com.br

2 Discentes de Mestrado do Curso de Pós-Graduação em Zootecnia, UFV, Viçosa, MG. E-mail: erika_mfigueiredo@yahoo.com. br; efc@gmail.com; amanda.dione@ufv.br

3 Prof ${ }^{\text {as }}$ Associado, Dept ${ }^{\mathrm{o}}$ de Zootecnia, UFV, Viçosa, MG. E-mail: flavia@ufv.br

4 Prof. Titular, Dept ${ }^{\circ}$ de Zootecnia, UFV, Viçosa, MG. E-mail: donzele@ufv.br

5 Discente de Doutorado do Curso de Pós-Graduação em Zootecnia, UFV, Viçosa, MG. E-mail: katiregia@yahoo.com.br;

${ }^{6}$ Discente de Graduação do Curso de Graduação em Medicina Veterinária, UFV, Viçosa, MG. E-mail: alineselos@yahoo.com.br

7 Discente de Graduação do Curso de Graduação em Zootecnia, UFV, Viçosa, MG. E-mail: rodrigofj2@gmail.com

Autor para correspondência
} 
$1.77^{\circ} \mathrm{C}$ and relative humidity of $70 \pm 5.82 \%$ corresponding to a calculated BGHI of $72 \pm 2.75$, which characterize thermoneutral environment. There was no effect of glutamine on feed intake, weight gain, and feed conversion of broilers. Glutamine had no influence on absolute and relative weights of carcass, breast, thigh, and drumstick of birds. There was not effect of dietary glutamine on mRNA expression of HSP70. Dietary glutamine did not affect performance and carcass traits of broilers from 21 to 42 days of age maintained in thermoneutral environment.

Key words: Birds, gene expression, HSP, thermal environment

\section{Introdução}

Com os avanços ocorridos nas áreas de genética, nutrição, manejo, ambiente e sanidade houve aumento considerável na velocidade de ganho de peso, redução da idade de abate e melhora na conversão alimentar de frangos de corte. Entretanto, a capacidade termorreguladora destes não evoluiu na mesma proporção, ficando o mesmo deficiente para enfrentar os desafios impostos pelo ambiente térmico, especialmente as temperaturas elevadas, refletindo em redução do consumo de ração e do ganho de peso das aves e consequentemente perdas econômicas para o produtor (LAGANÁ et al., 2005).

Alguns aditivos alimentares vêm sendo utilizados com o objetivo de melhorar o desempenho dos animais, entre os quais destacase a glutamina (BARTELL; BATAL, 2007), a qual fornece energia para células de rápida divisão (WU et al., 1995) como os enterócitos. Em condições de estresse, a glutamina se torna um aminoácido condicionalmente essencial, visto que há redução em níveis plasmáticos deste aminoácido (SANTOS; CAPERUTO; COSTA ROSA, 2007).

A glutamina aumenta a expressão molecular de proteínas do choque térmico (HSP's) responsáveis pela integridade celular (SANDERS; KON, 1991). $\mathrm{O}$ efeito da glutamina no aumento da expressão das HSP's ocorre de maneira dose-dependente, pois maiores concentrações de glutamina são necessárias de acordo com a intensidade do estresse, o que pode estar relacionado com a necessidade da célula de aumentar sua proteção e, consequentemente, sobreviver em condições de estresse (SINGLETON; WISCHMEYER 2007).
Desta forma, este estudo foi proposto para avaliar os efeitos de níveis de glutamina na ração no desempenho e carcaça de frangos de corte submetidos ao ambiente de termoneutralidade no período de 21 a 42 dias de idade.

\section{Material e Métodos}

O experimento foi conduzido no Laboratório de Bioclimatologia Animal do Departamento de Zootecnia, do Centro de Ciências Agrárias da Universidade Federal de Viçosa, em Viçosa, MG, de abril a setembro de 2012.

Foram utilizados 168 frangos de corte machos sexados da linhagem $\mathrm{COBB}^{\circledR}$, vacinados contra a doença de Marek no período de 21 a 42 dias de idade. Os frangos foram criados em galpão convencional até os 21 dias recebendo rações com $3.100 \mathrm{kcal} / \mathrm{kg}$ de energia metabolizável (EM), formuladas para satisfazer suas exigências nutricionais, conforme preconizado por Rostagno et al. (2005).

$\mathrm{O}$ delineamento experimental utilizado foi o inteiramente casualizado, com quatro tratamentos (ração basal e três níveis de glutamina), sete repetições e seis aves por unidade experimental. A unidade experimental foi representada pela gaiola.

Os tratamentos consistiram em uma ração basal com $3.000 \mathrm{kcal} / \mathrm{kg}$ de EM formulada para atender as exigências das aves na categoria estudada, segundo Rostagno et al. (2005) e três rações com níveis de 0,$50 ; 1,00$ e $1,50 \%$ de glutamina, obtidos a partir da inclusão da L-glutamina na ração em substituição ao amido (Tabela 1).

Aos 21 dias de idade, as aves foram pesadas e transferidas para as câmaras climáticas onde 
foram alojadas em gaiolas metálicas $(0,85 \times 0,85$

m) providas de comedouro e bebedouro do tipo calha. Proporcionou-se aos animais um ambiente de termoneutralidade para as aves conforme preconizado por COBB-VANTRESS (2008). Os frangos apresentaram peso médio inicial de 900,0 $\pm 4,71 \mathrm{~g}$.

Tabela 1. Composições centesimal e calculada das rações experimentais.

\begin{tabular}{|c|c|c|c|c|}
\hline \multirow{2}{*}{ Ingredientes (\%) } & \multirow{2}{*}{ Basal } & \multicolumn{3}{|c|}{ Nível de glutamina (\%) } \\
\hline & & 0,50 & 1,00 & 1,50 \\
\hline Milho & 58,682 & 58,682 & 58,682 & 58,682 \\
\hline Farelo de soja & 32,155 & 32,155 & 32,155 & 32,155 \\
\hline Óleo vegetal & 3,565 & 3,565 & 3,565 & 3,565 \\
\hline Fosfato bicálcico & 1,655 & 1,655 & 1,655 & 1,655 \\
\hline Calcário & 0,844 & 0,844 & 0,844 & 0,844 \\
\hline Sal comum & 0,471 & 0,471 & 0,471 & 0,471 \\
\hline Mistura vitamínica $^{1}$ & 0,200 & 0,200 & 0,200 & 0,200 \\
\hline Mistura mineral $^{2}$ & 0,200 & 0,200 & 0,200 & 0,200 \\
\hline Anticoccidiano $^{3}$ & 0,050 & 0,050 & 0,050 & 0,050 \\
\hline $\mathrm{BHT}^{4}$ & 0,010 & 0,010 & 0,010 & 0,010 \\
\hline Cloreto de colina ${ }^{5}$ & 0,125 & 0,125 & 0,125 & 0,125 \\
\hline Avilamicina $^{6}$ & 0,010 & 0,010 & 0,010 & 0,010 \\
\hline DL-metionina (99\%) & 0,227 & 0,227 & 0,227 & 0,227 \\
\hline L-lisina HCL (78\%) & 0,168 & 0,168 & 0,168 & 0,168 \\
\hline L- treonina $(98,5 \%)$ & 0,038 & 0,038 & 0,038 & 0,038 \\
\hline Amido & 1,600 & 1,100 & 0,600 & 0,100 \\
\hline L-Glutamina & 0,000 & 0,500 & 1,000 & 1,500 \\
\hline TOTAL & 100,00 & 100,00 & 100,00 & 100,00 \\
\hline \multicolumn{5}{|l|}{ Composição calculada } \\
\hline Proteína bruta (\%) & 19,743 & 20,343 & 20,943 & 20,643 \\
\hline Energia metab. (kcal/kg) & 3,100 & 3,100 & 3,100 & 3,100 \\
\hline Lisina digestível (\%) & 1,073 & 1,073 & 1,073 & 1,073 \\
\hline Met + cis digestíveis $(\%)$ & 0,773 & 0,773 & 0,773 & 0,773 \\
\hline Treonina digestível (\%) & 0,698 & 0,698 & 0,698 & 0,698 \\
\hline Triptofano digestível (\%) & 0,215 & 0,215 & 0,215 & 0,215 \\
\hline Valina digestível (\%) & 0,826 & 0,826 & 0,826 & 0,826 \\
\hline Isoleucina digestível (\%) & 0,770 & 0,770 & 0,770 & 0,770 \\
\hline Arginina digestível (\%) & 1,241 & 1,241 & 1,241 & 1,241 \\
\hline Leucina digestível (\%) & 1,605 & 1,605 & 1,605 & 1,605 \\
\hline Fenil.+tir.digestíveis (\%) & 1,521 & 1,521 & 1,521 & 1,521 \\
\hline Glicina + serina total $(\%)$ & 1,782 & 1,782 & 1,782 & 1,782 \\
\hline Sódio $(\%)$ & 0,205 & 0,205 & 0,205 & 0,205 \\
\hline Cálcio $(\%)$ & 0,824 & 0,824 & 0,824 & 0,824 \\
\hline Fósforo Disponível (\%) & 0,411 & 0,411 & 0,411 & 0,411 \\
\hline
\end{tabular}

${ }^{1}$ Conteúdo/kg: vit. A - 20.000.000 UI, vit. D3 -5.000.000.000 UI, vit. E - 40.500 UI, vit. B1 - 3.000 mg, vit. B2 - 12,0 g - vit. B6 - $5000 \mathrm{mg}$ - vit. B12 - $28.000 \mathrm{mcg}$ - biotina $60 \mathrm{mg}$ - niacina $87 \mathrm{~g}$ - ácido pantotênico - $29 \mathrm{~g}$, vit. K3 - $4.600 \mathrm{mg}$, ácido fólico $-1.600 \mathrm{mg}-10 \mathrm{~g}$, selênio $-250 \mathrm{mg}$, antioxidante BHT $-5.000 \mathrm{mg}$ e veículo q.s.p. $-1.000 \mathrm{~g}$.

${ }^{2}$ Conteúdo/kg: manganês, 156 g; ferro, 96 g; zinco, 110 g; cobre, 20 g; cobalto, 2 g; iodo, 1400 mg; e veículo q.s.p. 1.000 g.

${ }^{3}$ Salinomicina sódica $-60 \mathrm{ppm}$.

${ }^{4}$ Hidroxi-butil-tolueno.

${ }^{5} \mathrm{Cl}$-colina $-43,5 \mathrm{mg}$ de colina.

${ }^{6}$ Avilamicina $10 \%$.

Fonte: Software de formulação de rações para aves e suínos - Super Crac 5.0- versão Máster. 
As condições ambientais no interior das salas foram monitoradas diariamente, duas vezes ao dia (07h00 e 18h00), por meio de termômetros de bulbo seco, bulbo úmido e de globo negro mantidos no centro das salas a uma altura de 1,20 m. Estes dados foram convertidos no Índice de Temperatura de Globo e Umidade (ITGU), proposto por Buffington et al. (1981).

Durante todo o período experimental, o fornecimento das rações experimentais e de água às aves foi à vontade, sendo a água trocada três vezes ao dia. O programa de luz adotado foi o contínuo (24 horas de luz artificial), utilizando lâmpadas fluorescentes de $30 \mathrm{~W}$ cada.

Foram calculados o ganho de peso e o consumo de ração das aves dos 21 aos 42 dias de idade. A partir destes dados foi calculado a conversão alimentar.

Aos 42 dias, duas aves de cada unidade experimental com pesos mais próximos da média da gaiola foram submetidas a jejum alimentar de 12 horas. Em seguida, estas aves foram insensibilizadas via eletronarcose, abatidas por sangria mediante corte da artéria jugular, e após serem escaldadas e depenadas, foram evisceradas e as carcaças pesadas. Foram determinados os pesos absolutos e relativos da carcaça e dos cortes (peito, coxa e sobrecoxa).

Ainda, dentro de cada tratamento, outras três aves, com pesos mais próximos da média do respectivo tratamento $( \pm 10 \%)$, foram selecionadas para determinação da expressão de mRNA para a proteína do choque térmico de $70 \mathrm{kD}$ (HSP70), no músculo Pectoralis major. As aves foram insensibilizadas, abatidas por sangria e tiveram a pele da região peitoral retirada. Imediatamente após esse processo, foi coletado uma amostra de aproximadamente 2,0 $\mathrm{cm}$ de comprimento, $0,5 \mathrm{~cm}$ de largura e $0,5 \mathrm{~cm}$ de profundidade do músculo Pectoralis major direito, na região central da peça muscular. Em seguida, as amostras foram identificadas e imersas em RNA holder (BioAgency) e armazenadas em freezer a $-20^{\circ} \mathrm{C}$ até o momento da extração.

O mRNA total de cada amostra foi extraído utilizando-se o RNeasy Mini Kit (Qiagen) seguindose as recomendações do fabricante. Determinouse a concentração do mRNA total utilizando o espectrofotômetro Nano Vue Plus (GE Healthcare). A integridade do RNA foi avaliada utilizando gel de agarose a $1 \%$ e visualizado por meio da luz ultravioleta. O cDNA foi sintetizado utilizando o kit SuperScript ${ }^{\mathrm{TM}}$ III First-Strand Synthesis Super Mix (Invitrogen). Foram adicionados 6 microlitros do mRNA total, $1 \mu \mathrm{L}$ de oligo (dT) $(50 \mu \mathrm{M} \text { oligo(dT) })_{20}$ e $1 \mu \mathrm{L}$ de annealing buffer. A mistura foi incubada por 5 minutos a $65^{\circ} \mathrm{C}$ e em seguida, colocada no gelo por 1 minuto. Subsequentemente, foram adicionados $10 \mu \mathrm{L}$ de $2 x$ First-Strand Reaction Mix solution e $2 \mu \mathrm{L}$ da enzima SuperScript III reverse transcriptase. As amostras foram estocadas a $-20^{\circ} \mathrm{C}$ até a análise.

As sequências dos genes foram obtidas no website www.ncbi.nlm.nih.gov. Os primers foram desenhados de acordo com as sequências contidas em GeneBank, usando o website www.idtdna.com. As sequências de nucleótideos dos primers estão resumidas na Tabela 2.

Foram testados dois controles endógenos, os genes $\beta$-actina e GAPDH. Foi utilizado o gene da $\beta$-actina como controle endógeno porque houve menor variação em relação ao GAPDH, quando utilizado o programa GeNorm.(VANDESOMPELE et al., 2002).

Todos os ensaios foram realizados em um volume final de $25 \mu \mathrm{L}$ e em duplicata. Foi utilizado para a PCR em tempo real, o composto fluorescente SYBR ® Green PCR Master Mix (Qiagen). 
Tabela 2. Sequência dos primers HSP70, $\beta$-actina e GAPDH.

\begin{tabular}{ll}
\hline \multicolumn{1}{c}{ Genes } & \multicolumn{1}{c}{ Sequencia 5' $\rightarrow 3^{\prime}$} \\
\hline HSP70 & FP: CGTGACAATGCTGGCAATAAGCGA \\
$($ NM_001006685) & RP: TCAATCTCAATGCTGGCTTGCGTG \\
& FP: AGACATCAGGGTGTGATGGTTGGT \\
-actina & RP: TCCCAGTTGGTGACAATACCGTGT \\
& \\
GAPDH 205518$)$ & FP: CCCAGCAACATCAAATGGGCAGAT \\
$($ NM_204305) & RP: TGATAACACGCTTAGCACCACCCT \\
\hline
\end{tabular}

Fonte: Elaboração dos autores.

As condições de amplificação para todos os sistemas foram: $95^{\circ} \mathrm{C}$ durante 2 minutos, 40 ciclos de desnaturação a $95^{\circ} \mathrm{C}$ durante 15 segundos, e de extensão e anelamento a $60^{\circ} \mathrm{C}$ durante 60 segundos. As eficiências de amplificação representaram cerca de $100 \%$ em cada ciclo, e a expressão relativa foi calculada utilizando uma equação para corrigir diferenças de eficiência, como descrito por Pfaffl et al. (2001). Foram utilizadas as seguintes concentrações: para ambos os genes, $\beta$-actina e HSP70, foram utilizados uma concentração de 400 nM e de 50 nM de cDNA. A amplificação de genes-alvo foi realizada em poços diferentes e em duplicatas.

O delineamento experimental utilizado foi inteiramente casualizado, com três amostras por tratamento. Inicialmente, os dados em tempo real de PCR foram analisados conforme o modelo descrito abaixo.

$$
\mathrm{Y}_{i j k}=\mathrm{GP}_{i k}+\mathrm{D}_{i j k}+e_{i j k}
$$

Onde: $\mathrm{Y}_{i j k}$ quantifica o nível de expressão do gene i no animal $\mathrm{j}$ no tratamento $\mathrm{k}$; $\mathrm{GP}_{i k}$ efeito do gene i no tratamento $\mathrm{k} ; \mathrm{D}_{i j k}$ efeito específico da amostra aleatória (comum a ambos os genes), $\mathrm{D}_{i j k} \sim \mathrm{N}(0$, $\left.\sigma_{\mathrm{D}}^{2}\right)$; e $e_{i j k}$ erro aleatório, $e_{i j k} \sim \mathrm{N}\left(0, \sigma_{\mathrm{e}}^{2}\right)$.

As análises estatísticas das variáveis de desempenho e carcaça foram realizadas utilizandose o SAEG (UFV, 2003), por meio de modelos de regressão, utilizando o nível de significância de $10 \%$, em ambos os experimentos.
Os procedimentos estatísticos para a ánalise da expressão do mRNA da protéina HSP70 foram realizados utilizando o SAS 9.0 para Windows (Statistical Analysis System Institute, Inc., Carry, NC, EUA). A rotina \%QPCR_MIXED foi desenvolvida no SAS para analisar dados de PCR em tempo real. O PROC MIXED (STEIBEL et al., 2009) foi utilizado e para cada gene alvo e a comparação dos valores de expressão a partir do tratamento controle foi realizada por contrastes no PROC GLM, utilizando o teste t de Student.

Independente do efeito da interação entre o ambiente térmico e o nível de glutamina, ser ou não significativa, optou-se pelo desdobramento dos dados.

\section{Resultados e Discussão}

Durante o período experimental, a temperatura do ar e a de globo negro foi de $23,2 \pm 1,77^{\circ} \mathrm{C}$ e 24,3 $\pm 2,37^{\circ} \mathrm{C}$, respectivamente e a umidade relativa de $70 \pm 5,8 \%$, resultando em um ITGU calculado de $72 \pm 2,75$. Segundo COBB-VANTRESS (2008), a temperatura de 22 a $25^{\circ} \mathrm{C}$ e a umidade relativa de 60 a $75 \%$ caracterizam ambiente de termoneutralidade para frangos de corte dos 22 aos 42 dias de idade, podendo-se inferir que as aves deste estudo foram mantidas em condições de ambiente ótimo.

Os dados de desempenho das aves submetidas aos diferentes níveis de glutamina na ração encontram-se na Tabela 3. 
Tabela 3. Desempenho de frangos de corte recebendo rações com níveis diferentes de glutamina, mantidos em ambiente termoneutro dos 21 aos 42 dias de idade.

\begin{tabular}{|c|c|c|c|c|c|c|}
\hline \multirow{2}{*}{ Variável } & \multicolumn{4}{|c|}{ Nível de glutamina (\%) ${ }^{1}$} & \multirow{2}{*}{$\mathrm{P}$} & \multirow{2}{*}{$\mathrm{CV}(\%)$} \\
\hline & Basal & 0,50 & 1,00 & 1,50 & & \\
\hline Consumo de ração (g) & 3211 & 3141 & 3208 & 3138 & 0,05 & 2,38 \\
\hline Ganho de peso (g) & 1959 & 1908 & 1949 & 1918 & 0,05 & 2,31 \\
\hline Conversão alimentar (g/g) & 1,63 & 1,64 & 1,64 & 1,63 & 0,05 & 1,51 \\
\hline
\end{tabular}

${ }^{1}$ Efeito não significativo $(\mathrm{P}>0,10)$.

Fonte: Elaboração dos autores.

Os níveis de glutamina na ração não influenciaram $(\mathrm{P}>0,05)$ o consumo de ração dos frangos. Resultados semelhantes foram observados por Sakamoto et al. (2006) e Soltan (2009) que também não verificaram variação significativa na ingestão voluntária de alimentos das aves com a inclusão de glutamina na ração.

Com os dados de consumo de ração obtidos neste estudo ficou evidenciado que as aves em condições de termoneutralidade são capazes de metabolizar altos níveis de glutamina (1,50\%) na ração sem influenciar negativamente, o que não confirma o relato de Soltan (2009) que níveis de $1,50 \%$ e $2,0 \%$ de glutamina resultam em redução do consumo de alimentos dos frangos de 1 a 42 dias de idade.

$\mathrm{O}$ ganho de peso não variou $(\mathrm{P}>0,05)$ com o aumento dos níveis de glutamina na ração. Da mesma forma, Sakamoto et al. (2006) também não encontraram efeito positivo da suplementação de glutamina na ração na taxa de crescimento na fase de terminação. Por outro lado, Bartell e Batal (2007), Soltan (2009) e Fasina et al. (2010) verificaram que a inclusão de diferentes níveis de glutamina na ração aumentou o ganho de peso de aves nas fases inicial e final mantidas na termoneutralidade.

Considerando os relatos de Sakamoto et al. (2006) e Soltan (2009) de que a glutamina influencia positivamente a resposta imune das aves tornandoas mais resistentes à infecção, pode-se deduzir que a inconsistência dos resultados entre os trabalhos estaria relacionada, em parte, à possível diferença no nível imunológico das aves.
Não se observou efeito $(\mathrm{P}>0,05)$ dos níveis de glutamina sobre a conversão alimentar das aves. Estes dados estão consistentes com os encontrados por Bartell e Batal (2007) e Soltan (2009) que ao suplementar glutamina na ração dos frangos de corte não obtiveram efeito significativo do aminoácido na eficiência de ganho. No entanto, estudos conduzidos por Yi et al. (2001) revelaram melhora significativa na eficiência alimentar de frangos de corte quando alimentados com uma dieta suplementada com $1,0 \%$ de glutamina.

O fato de a suplementação da glutamina neste estudo não ter influenciado significativamente a conversão alimentar das aves, revelou que em boas condições ambientais como a adequada temperatura e o baixo nível de desafio do sistema imune em razão da higienização prévia das instalações, além da inclusão de promotor de crescimento nas rações experimentais, utilizados neste estudo, tornou-se dispensável a suplementação de glutamina para as aves expressarem sua máxima eficiência de crescimento.

Coerente com esta proposição, Dai et al. (2011) demonstraram que quando submetidos a desafio por alta temperatura, os frangos de corte aumentam a demanda de glutamina para alcançar sua máxima eficiência. Já Newsholme et al. (2001) relataram que a glutamina é um aminoácido essencial durante condições inflamatórias, tais como infecção e injúrias.

Os dados de carcaça e rendimento dos cortes das aves, submetidas aos diferentes níveis de glutamina na ração, encontram-se na Tabela 4. 
Tabela 4. Peso absoluto e rendimento de carcaça e de cortes nobres das aves recebendo rações com níveis de glutamina, mantidas em ambiente termoneutro aos 42 dias de idade.

\begin{tabular}{|c|c|c|c|c|c|c|}
\hline \multirow{2}{*}{ Variáveis } & \multicolumn{4}{|c|}{ Níveis de Glutamina (\%) ${ }^{1}$} & \multirow{2}{*}{$\mathrm{P}$} & \multirow{2}{*}{$\mathrm{CV}(\%)$} \\
\hline & Basal & 0,50 & 1,00 & 1,50 & & \\
\hline \multicolumn{7}{|c|}{ Peso Absoluto (g) } \\
\hline Carcaça & 2282 & 2203 & 2227 & 2158 & 0,05 & 3,30 \\
\hline Peito & 799 & 796 & 794 & 768 & 0,05 & 4,70 \\
\hline Coxa & 276 & 260 & 263 & 259 & 0,05 & 5,98 \\
\hline Sobrecoxa & 321 & 321 & 327 & 309 & 0,05 & 5,09 \\
\hline \multicolumn{7}{|c|}{ Rendimento (\%) } \\
\hline Carcaça & 83,13 & 82,47 & 82,35 & 82,40 & 0,05 & 0,82 \\
\hline Peito & 34,77 & 35,89 & 35,63 & 35,62 & 0,05 & 3,42 \\
\hline Coxa & 12,07 & 11,80 & 11,82 & 12,00 & 0,05 & 4,31 \\
\hline Sobrecoxa & 14,13 & 14,53 & 14,67 & 14,41 & 0,05 & 3,91 \\
\hline
\end{tabular}

${ }^{1}$ Efeito não significativo $(\mathrm{P}>0,10)$.

Fonte: Elaboração dos autores.

Não se verificou efeito $(\mathrm{P}>0,05)$ dos níveis de glutamina nos pesos absolutos e nos rendimentos de carcaça, peito, coxa e sobrecoxa das aves. Estes resultados estão coerentes com os obtidos por Zavarize et al. (2011) que avaliando níveis de glutamina até $1 \%$ na ração de frangos de 1 a 42 dias de idade, também não verificaram variação significativa no rendimento de carcaça e de cortes nobres.

Os dados obtidos para as variáveis de carcaça estão coerentes com os de desempenho, uma vez que, o fato de o ganho de peso e a conversão alimentar das aves não ter variado entre os tratamentos justificam os resultados de carcaça obtidos.

Os dados de expressão do mRNA da proteína HSP70 no músculo Pectoralis major de frangos de corte dos 21 aos 42 dias submetidas aos diferentes níveis de glutamina na ração encontram-se na Figura 1.

Ao analisar a expressão do mRNA da proteína HSP70 no músculo Pectoralis major, observou uma melhora não significativa na expressão do transcrito nos níveis de 1,00 e 1,50\% de glutamina.
$\mathrm{O}$ fato de a temperatura ter sido mantida dentro da faixa de termoneutralidade para estas aves, pode ser um dos principais fatores que justifica a falta de resposta significativa da expressão do mRNA da proteína HSP70 a suplementação de glutamina na ração neste estudo.

Segundo Dai et al. (2009), a glutamina é um aminoácido condicionalmente essencial e pode aumentar a expressão in vivo da HSP70 induzida pelo estresse e melhorar a sobrevivência das células quanto a uma variedade de estímulos estressantes. Confirmando relatos de Zulkifli et al. (2009) que verificaram que frangos de corte produzidos em galpões convencionais abertos, os quais apresentam oscilações de temperatura, desenvolvem maior expressão da HSP70, suportando o estresse térmico por calor durante o transporte com melhor eficiência em comparação a frangos criados em aviário fechado com ambiente controlado. 
Figura 1. Expressão relativa do mRNA da proteína do choque térmico (HSP70) no músculo Pectoralis major de frangos de corte mantidos em ambiente de termoneutralidade, aos 42 dias de idade.

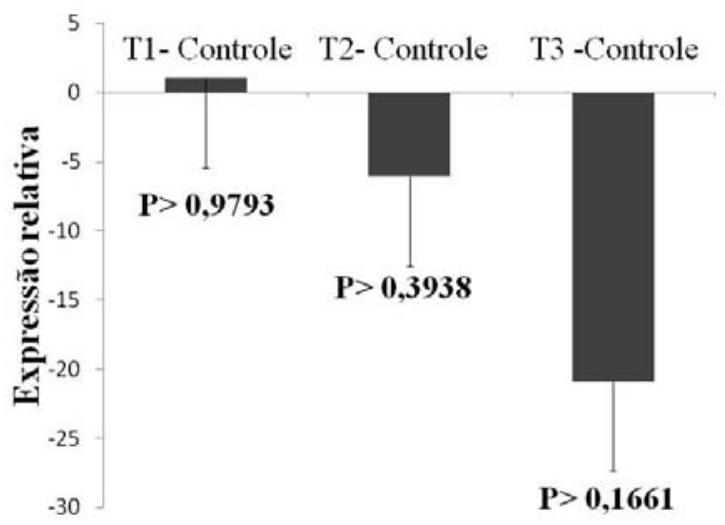

Fonte: Elaboração dos autores.

Conclui-se que os níveis de glutamina na ração não influenciam as variáveis de desempenho e características de carcaça de frangos de corte mantidos em ambiente de termoneutralidade dos 21 aos 42 dias de idade.

\section{Agradecimentos}

À FAPEMIG (Fundação de Amparo à Pesquisa do Estado de Minas Gerais) e ao INCTca (Instituto Nacional de Ciência e Tecnologia de ciência Animal), pelo apoio e incentivo à pesquisa científica, possibilitando a realização do estudo.

\section{Comitê de Ética}

Esta pesquisa foi previamente aprovada pelo Comitê de Ética (CEUA/UFV) sob o processo $n^{\circ}$ 24/2012, estando de acordo com os princípios éticos da experimentação animal.

\section{Referências}

BARTELL, S. M.; BATAL, A. B. The effect of supplemental glutamine on growth performance, development of the gastrointestinal tract, and humoral immune response of broilers. Poultry Science, Savoy, v. 86, n. 9, p. 1940-1947, 2007.
BUFFINGTON, D. E.; COLAZZO-AROCHO, A.; CANTON, G. H.; PITT, D.; THATCHER, W. W.; COLLIER, R. J. Black globe-humidity index (BGHI) as comfort equation for dairy cows. Transaction of the $A S A E$, St. Joseph, v. 24, n. 3, p. 711-714, 1981.

COBB-VANTRESS. Manual de manejo de frangos de corte cobb. Guapiaçu: Cobb-Vantress Brasil, 2008. 66 p.

DAI, S. F.; GAO, F.; ZHANG, W. H; SONG, S. X.; XU, X. L.; ZHOU, G. H. Effects of dietary glutamine and gamma-amino butyric acid on performance, carcass Characteristics and serum parameters in broilers under circular heat stress. Animal Feed Science and Technology, Amsterdam, v. 168, n. 1-2, p. 51-60, 2011.

DAI, S. F.; WANG, L. K.; WEN, A. Y.; WANG, L. X.; JIN, G. M. Dietary glutamine supplementation improves growth performance, meat quality and colour stability of broilers under heat stress. British Poultry Science, Edinburgh, v. 50, n. 3, p. 333-340, 2009.

FASINA, Y. O.; BOWERS, J. B.; HESS, J. B.; MCKEE, S. R. Effect of dietary glutamine supplementation on Salmonella colonization in the ceca of young broiler chicks. Poultry Science, Savoy, v. 89, n. 5, p. 1042-1048, 2010.

LAGANÁ, C.; RIBEIRO, A. M. L.; KESSLER, A. M.; SOUZA, E. N. Influência do nível nutricional da dieta no rendimento de órgãos e gordura abdominal em frangos estressados por calor. Revista Brasileira de Saúde e Produção Animal, Salvador, v. 6, n. 2, p. 59-66, 2005.

NEWSHOLME, P. Why is L-Glutamine metabolism important to cells of the immune system in health, post injury, surgery or infection? Journal Nutrition, Bethesda, v. 131, n. 9, p. 2515S-2522S, 2001. 
PFAFFL, M. W. A new mathematical model for relative quantification in real time RT-PCR. Nucleic Acids Research, Seattle, v. 29, n. 9, p. 45, 2001.

ROSTAGNO, H. S.; ALBINO, L. F. T.; DONZELE, J. L.; GOMES, P. C.; OLIVEIRA, R. F. M.; LOPES, D. C.; FERREIRA, A. S.; BARRETO, S. L. T. Tabelas brasileiras para aves e suinos: composição de alimentos e exigências nutricionais. 2. ed. Viçosa, MG: UFV, Departamento de Zootecnia, 2005. 186 p.

SAKAMOTO, M. I.; MURAKAMI, A. E.; SILVEIRA, T. G. V.; FERNANDES, J. I. M.; OLIVEIRA, C. A. L. Influence of glutamine and vitamin $\mathrm{E}$ on the performance and the immune response of broiler chickens. Brazilian Journal Poultry Science, Campinas, v. 8, n. 4, p. 243249, 2006.

SANDERS, M. M.; KON, C. Glutamine is a powerfull effector of heat shock protein expression in drosophila Kc cells. Journal of Cellular Physiology, Bethesda, v. 146, n. 1, p. 180-190, 1991.

SANTOS, R. V. T.; CAPERUTO, E. C.; COSTA ROSA, L. F. B. P. Effects of acute exhaustive physical exercise upon glutamine metabolism of lymphocytes from trained rats. Life Science, Ohio, v. 80, n. 6, p. 573-8, 2007.

SINGLETON, K. D.; WISCHMEYER, P. E. Glutamine protection against sepsis and lung injury is dependent on heat shock protein 70 expression. American Journal Physiology, Bethesda, v. 292, n. 5, p. 1839-45, 2007.

SOLTAN, M. A. Influence of dietary glutamine supplementation on growth performance, small intestinal morphology, immune response and some blood parameters of broiler chickens. International Journal of Poultry Science, Pakistan, v. 8, n. 1, p. 60-68, 2009.
STEIBEL, J. P.; POLETTO, R.; COUSSENS, P. M.; ROSA, G. J. M. A powerful and flexible linear mixed model framework for the analysis of relative quantification RT-PCR data. Genomics, Boston, v. 94, n. 2, p. 146-152, 2009.

UNIVERSIDADE FEDERAL DE VIÇOSA - UFV. SAEG - Sistema de análises estatísticas e genéticas. Versão 8.1. Viçosa, MG, 2003.

VANDESOMPELE, J.; PRETER, K. de; PATTYN, F.; POPPE, B.; VAN ROY, N.; PAEPE, A.; SPELEMAN, F. Accurate normalization of real-time quantitative RT-PCR data by geometric averaging of multiple internal control genes. Genome Biology, London, v. 3, n. 7, p. 03-07, 2002.

WU, G.; FLYNN, N. N. E.; YAN, W.; BARSTOW, D. G. J. R. Glutamine metabolism in chick enterocyte:absence of pyrroline-5-synthase and citrulline synthesis. Biochemical Journal, London, v. 306, n. 3, p. 717-721, 1995.

YI, G. F.; ALLEE, G. L.; FRANK, J. W.; SPENCER, J. D.; TOUCHETTE, K. J. Impact of glutamine, menhaden fish meal, and spray-dried plasma on the growth and intestinal morphology of broilers. Poultry Science, Savoy, v. 80, p. 201, 2001. Supplement 1.

ZAVARIZE, K. C.; SARTORI, J. R.; PELÍCIA, V. C.; PEZZATO, A. C.; ARAUJO, P. C.; STRADIOTTI, A. C. E.; MADEIRA, L. A. Glutamina e nucleotídeos na dieta de frangos de corte criados no sistema alternativo. Archivos de Zootecnia, Córdoba, v. 60, n. 232, p. 913920, 2011.

ZULKIFLI, I.; AL-AQIL, A.; OMAR, A. R.; SAZILI, A. Q.; RAJION, M. A. Crating and heat stress influence blood parameters and heat shock protein 70 expression in broiler chickens showing short or long tonic immobility reactions. Poultry Science, Savoy, v. 88, n. 3, p. 471-476, 2009. 
